\title{
LAS RELACIONES PÚBLICAS, LA COMUNICACIÓN VISUAL Y EL MITO DEL CAPITALISMO TRANSNACIONAL (1943-1950)
}

\author{
PUBLIC RELATIONS, VISUAL COMMUNICATION AND THE MYTH \\ OF TRANSNATIONAL CAPITALISM (1943-1950)
}

Edward Goyeneche-Gómez*

Universidad de La Sabana. Colombia

\begin{abstract}
RESUMEN: El artículo estudia las transformaciones de las relaciones públicas (PR) internacionales, entre 1943 y 1950, en el contexto de la industria privada norteamericana, vinculado al desarrollo del Proyecto Fotográfico de la Standard Oil Company (New Jersey), que buscaba la construcción de un nuevo mito sobre el capitalismo transnacional que conectara la economía, la sociedad y la cultura, más allá de los estados nacionales, en medio de una crisis discursiva generada por la Segunda Guerra Mundial y las ideologías populistas y folcloristas dominantes. Se demuestra que esa multinacional, buscando enfrentar una crisis de imagen, revolucionó el campo de las relaciones públicas, a partir del uso de un aparato de comunicación visual denominado fotografía documental industrial, que permitiría conectar de manera inédita y contradictoria, en torno a la historia del petróleo, a Estados Unidos con sociedades de todo el globo, principalmente con América Latina.
\end{abstract}

PALABRAS CLAVE: Relaciones públicas; Industria petrolera; Fotografía documental; Capitalismo.

\begin{abstract}
The article studies the transformations of international public relations $(P R)$, between 1943 and 1950, in the context of North American private industry, linked to the development of the Photographic Project of the Standard Oil Company (New Jersey), which sought the construction of a new myth about transnational capitalism, which will connect the economy, society and culture, beyond national states, amid a discursive crisis generated by World War II and the dominant populist and folklorist ideologies. It is demonstrated that this multinational, seeking to face an image crisis, revolutionized the field of public relations, from the use of a visual communication device called industrial documentary photography, which would allow to connect in an unpublished and contradictory way, around the history of oil, to the United States with societies around the globe, mainly with Latin America.
\end{abstract}

KEYWORDS: Public relations; Oil industry; Photography; Capitalism.

* Correspondencia a: Edward Goyeneche-Gómez. Universidad de La Sabana. Facultad de Comunicación. Campus del Puente del Común, Km. 7, Autopista Norte de Bogotá. Chía, Cundinamarca (Colombia) - edward.goyeneche@unisabana.edu.co - https:// orcid.org/0000-0003-0746-4310

Cómo citar: Goyeneche-Gómez, Edward (2021). «Las relaciones públicas, la comunicación visual y el mito del capitalismo transnacional (1943-1950)»; Historia Contemporánea, 66, 493-522. (https://doi.org/10.1387/hc.21124).

Recibido: 10 octubre, 2019; aceptado: 26 enero, 2020.

ISSN 1130-2402 - eISSN 2340-0277 / (C) 2020 UPV/EHU

cc) $\rightleftharpoons$ Esta obra está bajo una Licencia

creative Commons Atribución-NoComercial-SinDerivadas 4.0 Internacional 


\section{Introducción: la crisis de las relaciones públicas de la industria petrolera privada}

El 2 de noviembre de 1942, Earl Newsom de la consultora Earl Newsom Company, uno de los más importantes asesores de relaciones públicas en la historia de la industria privada de los Estados Unidos, escribió una serie de observaciones, como parte de su trabajo para la Standard Oil Company (New Jersey) (SONJ), sobre la ruta que debía seguir la compañía en el campo de las relaciones públicas, para superar la mala imagen que tenía en la mente del público norteamericano e internacional. El memorando, que partía de los datos estadísticos recopilados por el reconocido encuestador Elmo Roper, quien se había desempeñado como analista de opinión para George Gallup, buscaba redefinir las políticas de relaciones públicas de la SONJ - en medio del agitado clima político y social que se vivía en el país por la Segunda Guerra Mundial y de los problemas de comunicación e imagen de la empresa - en torno a un cambio en la visión sobre la relación entre la industria, la democracia y la sociedad, centrada en un contexto más transnacional que nacional ${ }^{1}$.

Según escribe Newsom, el conocimiento humano está necesariamente limitado a la selección de trozos de evidencia que provienen de distintas fuentes, cuya mezcla supone la construcción de una imagen mental; pero no se trata de una instantánea mental, sino de un montaje, de una combinación de varias imágenes para producir una imagen que es distinta en sí misma y no meramente la suma total de las imágenes que lo componen ${ }^{2}$. Esto permitía explicar, según Newsom, por qué hasta ese momento, supuestamente, la empresa seguía teniendo una imagen distorsionada en el público, a pesar de los cambios estructurales que venía implementando desde $1927^{3}$. El 7 de junio de 1946, le escribió a Mr. George Freyermuth, del departamento de PR de la SONJ, recordándole la importancia de contribuir a la construcción constante de una «democracia industrial» que garantizara la viabilidad del proyecto liberal del capitalismo, vinculando a los artistas como parte del proceso. Esta idea, que parece tan obvia para la sociedad moderna, cobra mucha importancia, a partir de los años cuarenta, en los Estados Unidos, ante el debilitamiento constante de la imagen de las corporaciones industriales generada por la crisis de la gran de-

\footnotetext{
1 Newsom, 1942, p. 3.

2 Newsom, 1942, p. 4.

3 Newsom, 1942, p. 6.
} 
presión y el resquebrajamiento del trabajo liberal como principal lazo social de la sociedad moderna. Según Newsom, la «democracia industrial», debía retomar el liderazgo: «La forma de comenzar es hacer que la democracia funcione, mejor que el comunismo o el socialismo o cualquier otro sistema. Esto solo se puede hacer si la democracia industrial cumple con el desafío de esta era y toma progresivamente el liderazgo» ${ }^{4}$.

Las preocupaciones sobre la imagen pública de la compañía se vincularon a tres aspectos fundamentales. En primer lugar, la mayoría del público creía que todas las Standard Oil Companies eran una sola, y no conocía la historia de la división original en 7. En segundo lugar, se recuerda que la crisis de la imagen de las compañías petroleras norteamericanas se originó, en parte, en el escándalo de I. G. Farben, por su colaboración con empresas alemanas del nazismo. Y, en tercer lugar, se marcó el desconocimiento que tenía el gran público de las contribuciones de la compañía al éxito de los Estados Unidos en la guerra y a su éxito en lo económico. Las sugerencias de Roper para cambiar esta imagen estaban vinculadas a un megaproyecto sociocultural, de carácter transnacional, que implicaba la demostración factual del interés de la compañía en el bienestar de la sociedad. De entrada, el memorando señalaba la importancia de que la compañía tuviera una opinión favorable entre los gobiernos y la gente de los países amigos en el extranjero, y el reconocimiento de la obligación que tenía la empresa con la sociedad más allá de las fronteras, pues el negocio del petróleo era internacional ${ }^{5}$.

Como lo señala Stuart Ewen, durante los años cuarenta la corporación SONJ tuvo que aceptar que la historia de sus relaciones con el público, asociadas a la historia de la familia Rockefeller, no había sido afortunada. Resultaba indispensable «educar» de nuevo al público respecto del papel económico, social y político de la compañía; y sobre el rol de los grandes líderes económicos, quienes, desde un lugar privado, nunca estuvieron obligados a explicar sus actos o decisiones ${ }^{6}$.

Entre 1943 y 1945, la SONJ reestructuró la organización, la política y el programa de relaciones públicas y de responsabilidad corporativa de la compañía. Las primeras acciones en la nueva estrategia de relaciones públicas buscaban superar los programas propagandísticos ${ }^{7}$. La idea

\footnotetext{
${ }^{4}$ Newsom, 1946, traducción propia.

5 Newsom, 1942, p. 3.

6 Ewen, 1996, p. 100.

7 Larson, Knowlton, and Popple, 1971, p. 446.
} 
de la construcción y difusión de hechos, científicamente comprobables y periodísticamente incontrovertibles, estaba ahora en la base de la estrategia, que suponía, además, una actitud positiva y agradable respecto a la presentación de esos hechos, y una visión distinta de la responsabilidad corporativa. La nueva estructura, que incluía también un programa de investigación, supuso una división social del trabajo distinta en el mismo departamento de relaciones públicas ${ }^{8}$.

El Proyecto Fotográfico de la Standard Oil Company (New Jersey) surgió en ese contexto de transformación de las políticas de relaciones públicas que ya no se reducían a la provisión de información para los medios de comunicación de masas, como respuesta a los problemas, sino a la producción permanente de productos de comunicación soportados en estrategias de gran alcance, que se conectaran con esferas artísticas, educativas, sociales, políticas y por supuesto económicas; y que permitieran establecer una nueva comunicación con el público. Para ello, se integró a la propia noción de relaciones públicas, en el marco conceptual del proyecto, el problema de la fotografía documental y de los usos de las imágenes visuales como eje central de esa transformación. Este artículo analiza, en este sentido, el caso del Proyecto Fotográfico de la Standard Oil Company (New Jersey) desarrollado por la SONJ para enfrentar su crisis de relaciones públicas, donde la comunicación visual, la fotografía documental, tuvo un papel preponderante en la construcción de una nueva representación mítica de la industria petrolera y su relación con la democracia capitalista transnacional.

\section{El problema de las relaciones públicas y las imágenes visuales: discusión conceptual y observaciones metodológicas}

En la discusión histórica sobre el problema concreto de las relaciones públicas, que se está analizando, los estudios se han centrado en una conceptualización que mezcla, sin crítica y diferenciación alguna, varias nociones, que, aunque se relacionan entre sí, solo es posible usar en sus propios contextos de construcción: propaganda, diplomacia pública, diplomacia cultural, poder suave y relaciones públicas (PR). Las estrategias de persuasión y propaganda cobraron fuerza durante el periodo entregue-

${ }^{8}$ Larson, Knowlton, and Popple, 1971, p. 629. 
rras y fueron utilizadas por el propio gobierno de Franklin D. Roosevelt en su proyecto retórico fotográfico documental humanista y populista para el New Deal. Cabe anotar que en el campo de las teorías de comunicación se ha analizado suficientemente este fenómeno durante todo el siglo XX en contextos específicos y desde enfoques particulares. Sin embargo, se debe señalar que, para la época, los estudios de comunicación de masas estaban centrados en tres narrativas. En primer lugar, las teorías liberales de los medios de comunicación de masas, que venían desarrollándose desde el siglo XVII, partían de una visión normativa positiva de la comunicación asociada al concepto de público y a las determinaciones de la democracia liberal: los medios modernos fortalecerían la democracia ${ }^{9}$.

En segundo lugar, desde 1927 había surgido la corriente de investigación Mass Communication Research que estuvo liderada por Harold D. Lasswell, de la Universidad de Yale, y que se institucionalizó, con la continuidad del trabajo de Paul Felix Lazarsfeld, Robert King Merton, Kurt Lewin, Carl Hovland, Claude Shannon, Norbert Wienner, que venían de disciplinas distintas como la sociología, la psicología y las matemáticas. Los estudios de Lasswell comenzaron como estudios de propaganda en los años treinta, con el caso de su análisis fundacional Propaganda Technique in the World War $I^{10}$, y luego evolucionaron rápidamente hacia la teoría del análisis funcional. Y, en tercer lugar, la otra línea teórico-empírica que se estaba desarrollando en esa época se apoyaba en el concepto de relaciones públicas (PR), cuya definición y aplicación - teorizada en parte por Edward Bernays quien delinearía los primeros protocolos de persuasión - se transformaría significativamente durante el siglo XX. Lo importante aquí es marcar que el uso de la propaganda había acumulado, para la Segunda Guerra Mundial, suficientes connotaciones negativas, aunque se siguiera usando indiscriminadamente en la práctica. Esto llevaría a redefinir, posteriormente, el trabajo de la propaganda institucional bajo conceptos como el de relaciones públicas.

La propaganda se vinculó, casi siempre, a procesos de comunicación verticales de una sola vía, mientras que los nuevos conceptos de PR suponían, al menos de antemano, un sentido interactivo, «a two way-affair» ${ }^{11}$. María Luisa Azpíroz señala que el término diplomacia pública, por ejemplo, fue definido por primera vez en 1965 por Edmund Guillon para dife-

\footnotetext{
9 Curran, 2002, p. 4.

10 Véase Lasswell, 1927.

11 Cramer and Prutsch, 2012, p. 20.
} 
renciarlo de la diplomacia tradicional. El concepto abarcaba procesos de comunicación interculturales, y reconocía el papel que «otro de tipo de organizaciones hacían de la diplomacia pública (por ejemplo organizaciones internacionales como la UE, la OTAN o la ONU, organizaciones no gubernamentales - ONG - o corporaciones)» como un instrumento al servicio de los intereses de la imagen y de la política exterior, apuntando a llegar no solo a los gobiernos sino, principalmente, a la opinión pública y a los ciudadanos del común, y no llevando necesariamente un mensaje político explícito, dado el tipo de actividades que involucraba como eventos o productos culturales ${ }^{12}$. Posteriormente, el concepto de diplomacia cultural, a pesar de que puede asimilarse a lo que hicieron los Estados y empresas desde los años cuarenta del siglo Xx, tomó mucha fuerza a partir de la difusión, viralización y uso desproporciado de la noción poder suave, acuñada en 1990, por Joseph Nye ${ }^{13}$.

$\mathrm{Al}$ respecto, Uwe Lübken señala que, por ejemplo, para el caso de la influencia de los Estados Unidos en América Latina, durante la Segunda Guerra Mundial, el uso de la diplomacia cultural resultó absolutamente obvio y efectivo, aunque los propios funcionarios norteamericanos no entendían muy bien de qué se trataba el asunto, lo que también llevó a varios fracasos ${ }^{14}$. Los problemas en las relaciones entre Estados Unidos y América Latina, por ejemplo, que implicaron la ejecución de la política de The Good Neighbor policy y la creación de la Office of Inter-American Affairs, OIAA, incluían la necesidad del gobierno de los Estados Unidos de mediar en los conflictos que las empresas norteamericanas, principalmente petroleras, tenían con los gobiernos locales y los trabajadores de América Latina.

Como se verá más adelante, en el caso que se está analizando, fue fundamental la transformación del concepto de relaciones públicas en relación con los procesos de comunicación que implicaban los usos de imágenes visuales. La capacidad de persuasión por medio de las imágenes había estado en el programa de los estudios de psicología social y de las masas, desde el siglo XIX. Las preguntas sobre cómo podían afectar las imágenes las creencias, actitudes, opiniones y comportamientos estaban a la orden del día en los extensos estudios de comunicación que comenzaron a desarrollarse a partir de la década de los veinte. Pero más allá de la teorización

\footnotetext{
12 Azpíroz, 2012,pp. 13-14.

13 Nye, 1990, p. 528.

14 Lübken, 2012, p. 59.
} 
sobre los fenómenos de comunicación de masas, que siempre estuvieron bajo sospecha por la falta de rigor científico y comprobación empírica, lo que resultaba claro, en la práctica, era que el público era muy consciente de la aplicación de técnicas retóricas y persuasivas; y que se mostraba reacio a las tretas propagandísticas o publicitarias groseras ${ }^{15}$.

Los usos sociales de imágenes visuales se constituyeron, en este sentido, en una alternativa para desarrollar efectos retóricos más elaborados y efectivos, los cuales, tal como lo indica Ewen, estaban generando cambios significativos en las técnicas de la persuasión. La búsqueda comenzó a girar en torno a la construcción de evidencias de naturaleza factual que permitieran hacer más convincentes los mensajes ${ }^{16}$. Los años veinte ofrecieron un marco amplio de discusión sobre el problema del efecto de la imagen, principalmente fotográfica, que resultaba mucho más efectiva que la verbal en la comunicación de la verdad, sobre todo la fotografía documental ${ }^{17}$.

Para este análisis, es fundamental tener en cuenta que en todos los documentos institucionales, oficiales, del Proyecto Fotográfico de la Standard Oil Company (New Jersey), la conceptualización del proyecto se centra en el problema de la relación entre las relaciones públicas, la fotografía documental y la industria. Esto implica que no se intentará apelar a otro marco de explicación, para, en lo posible, evitar caer en el anacronismo que produce el uso de conceptos que están por fuera de su tiempo histórico de construcción.

El punto de partida metodológico es la construcción de un modelo de investigación relacional, un «archivo del problema», soportado en un corpus documental, sistematizado en una base de datos, que permitió analizar los documentos tanto escritos como visuales, en conexión con hipótesis específicas de investigación en virtud del análisis histórico. Se usaron en este sentido elementos transversales de método de la historia comparada para comprender los problemas vinculados a las relaciones e intercambios entre sociedades. Nos enfrentamos al análisis de un sistema transnacional de conexiones, cristalizado en El Proyecto Fotográfico de la Standard Oil Company (New Jersey), en el que se concretan relaciones complejas entre sociedades, entre sistemas económicos y culturales, y entre modelos específicos de conocimiento, representación y de comunicación; que tras-

\footnotetext{
15 Ewen, 1996, p. 197.

16 Blair, 2004, p. 41.

17 Ewen, 1996, p. 198.
} 
cienden el estado nación y que constituyen nuevas formas de globalización ${ }^{18}$. El análisis documental específico, desde lo metodológico, se centra un corpus de documentos primarios, escritos y visuales, generados por la propia compañía SONJ, entre 1943 y 1950, que se encuentran en los archivos Standard Oil (New Jersey) Collection y Roy Stryker (1893-1975) Papers. 1912-1972, ubicados en la sección Photographic Archives de la University of Louisville, en Estados Unidos.

\section{El contexto de los cambios en las políticas de comunicación de la Standard Oil Company (New Jersey) y su influencia en América Latina}

Para Bennett H. Wall, SONJ fue una de las corporaciones que, a pesar de las importantes transformaciones que ocurrieron durante la Segunda Guerra Mundial y la postguerra, logró mantener y consolidar su liderazgo hacia la mitad del siglo Xx, gracias, en parte, al equilibrio que la compañía encontró entre el control y la organización efectiva, el balance entre la descentralización y la centralización, y la flexibilidad y capacidad de adaptación a una cambiante estructura geopolítica. Los cambios más importantes en la nueva estructura organizativa que se consolidó a mitad de siglo XX se dieron, en parte, por la llegada a la presidencia de la compañía de Eugene Holman, el hombre petrolero por definición, en 1944, quien ya se desempeñaba como director desde algunos años atrás, y que presidió la SONJ hasta $1960^{19}$.

El papel de Eugene Holman resulta significativo para El Proyecto Fotográfico de la Standard Oil Company (New Jersey), porque dirigió la filial de la SONJ en Venezuela, Creole Petroleum Corporation, y conoció en detalle la operación petrolera en Sudamérica; porque bajo su mando se puso en marcha una revolución en la comunicación corporativa cuyas implicaciones sociales superaban lo meramente económico; y por su cercanía con uno de los accionistas de la empresa y prestigioso político norteamericano Nelson A. Rockefeller, quien estuvo en la junta directiva de la Creole. Desde sus inicios, como lo explican Larson, Knowlton y Popple en su History of Standard Oil Company (New Jersey), la compañía mantuvo políticas expansionistas, utilizando distintas estrategias para la ex-

\footnotetext{
18 Seigel, 2005, p. 63.

19 Wall, 1988, p. 11.
} 
ploración, producción y distribución de petróleo en todo el mundo, que incluyeron la negociación de concesiones y la compra de filiales en distintos países, incluyendo varios de Sudamérica ${ }^{20}$.

A pesar de las tensas relaciones que se presentaron durante la disolución de la original Standard Oil, después de la Primera Guerra Mundial, el Estado norteamericano instó a las compañías petroleras del país a adquirir reservas y a explotar los campos en distintos lugares del mundo, con fines geopolíticos, de seguridad y defensa nacional que le traerían beneficios al pueblo de los Estados Unidos. Rápidamente la SONJ adquirió la propiedad de producción en Perú, México, Colombia y Venezuela donde implementó una estrategia agresiva de exploración y explotación de los campos petrolíferos con fines estrictamente monetarios que no beneficiaban, casi de ningún modo, a estos Estados y a sus sociedades. Pero la crisis económica y los problemas administrativos, originados a partir de 1927, durante la gran depresión, obligaron a repensar las estrategias de relaciones tanto productivas como políticas con los países en cuestión.

Estas transformaciones, que tardaron más de dos décadas en implementarse, incluirían el problema de la comunicación, las relaciones públicas y la construcción de la imagen de la compañía alrededor del mundo. Entre 1927 y 1939 varios países de Sudamérica, concebidos geopolíticamente como parte del mundo no-comunista, vinculados a la SONJ por medio de la Imperial Oil Limited, con sede en Canadá, se convirtieron en prioridad para su agenda política. Las empresas filiales de la Imperial Oil que operaban en Colombia y Perú - The Tropical Oil Company, International Petroleum Company y Limited - con relativa independencia, comenzaron a tener mayor control por parte de los ejecutivos de las sedes centrales de la SONJ. Cabe anotar que en el caso de Perú los conflictos entre las empresas filiales de la SONJ y los gobiernos y el Estado peruano se extendieron durante todo el periodo de la explotación petrolera de los campos La Brea y Pariñas, en Talara, entre 1914 y 1968, a cargo de la IPC como filial de la Imperial Oil Company, campos que terminaron siendo expropiados por el gobierno por la vía militar.

En Colombia, The Tropical Oil Company - que luego fue absorbida por la SONJ por medio de la International Petroleum Company filial de la Imperial Oil- había adquirido los campos petrolíferos de la Concesión de Mares que, como lo señala Eduardo Sáenz Rovner, representa-

${ }^{20}$ Larson, Knowlton, and Popple, 1971, p. 2. 
ban, en 1927, la principal fuente de explotación fuera de los Estados Uni$\operatorname{dos}^{21}$. Para la SONJ, la llave de su presencia en Sudamérica estaba en Venezuela, cuya actividad petrolera la operaba la filial Creole Petroleum Corporation bajo una concesión que llegó hasta 1975. En la década de los cuarenta, del siglo xx, Venezuela llegó a ser el máximo productor de petróleo del mundo, justo cuando se desarrolló El Proyecto Fotográfico de la Standard Oil Company (New Jersey), lo que para la SONJ representaba millonarias ganancias sobre todo durante la Segunda Guerra Mundial ${ }^{22}$. Por eso cuando empezaron los cambios en las estrategias corporativas, comerciales y geopolíticas de la SONJ, Sudamérica estaba en el centro de la escena.

No obstante, los cambios generados en esas políticas corporativas tuvieron un alcance mucho mayor respecto a una redefinición del papel de la industria petrolera en la vida humana y en sus relaciones con la sociedad, la economía y la política. A partir de 1941, SONJ comienza una transición fundamental en esta área, en el difícil contexto transnacional de la Segunda Guerra Mundial, vinculada a las complejas necesidades internacionales de proyección de la compañía. La guerra obligó a la SONJ a redefinir sus políticas de relaciones públicas debido, justamente, al papel que la propia empresa estaba desempeñando en la guerra y al cuidado de sus propias, presentes y futuras, inversiones en la industria petrolera transnacional. En 1942, varias de las compañías Standard Oil, incluyendo la SONJ, tuvieron que enfrentar tres comités - de Truman, de Bone y de Kilgore - para explicar su participación en el abastecimiento de combustible de la maquinaria alemana usada durante la Segunda Guerra Mundial. El caso, que vinculó a la oscura compañía alemana IG Farben, cooperadora comprobada del régimen nazi, como proveedora de gas y de caucho por ejemplo, incluyó, además, serios cuestionamientos sobre la participación de las petroleras norteamericanas en el diseño, desarrollo y financiación, en laboratorios estadounidenses, de un tipo de "gasolina sintética» que le permitiría al gobierno alemán, según las acusaciones de la época, ir a la guerra. Estos hechos generarían, por defecto y de manera obvia, una imagen muy negativa de la industria petrolera entre el público estadounidense ${ }^{23}$.

\footnotetext{
21 Sáenz Rovner, 2002, p. 121.

22 Wall, 1988, p. 398.

${ }^{23}$ Ewen, 1996, pp. 349-353.
} 
Pero la crisis no concernía solo a la imagen de las petroleras. Tras el New Deal, en medio de la guerra, tanto el gobierno como las empresas privadas comenzaron a preocuparse por el lugar que debían ocupar las industrias y las compañías, en un entorno de restructuración del mercado capitalista transnacional, en el desarrollo y consolidación del país. Si en los años treinta la preocupación gubernamental tenía fundamentalmente un carácter social, en los cuarenta tuvo un carácter primordialmente económico. La contribución de las compañías norteamericanas a la guerra debía servir como punto de partida para insertar de manera definitiva a la industria en el imaginario colectivo y en la estructura del Estado, de tal manera que se eliminaran las confrontaciones entre el mercado y la sociedad, reivindicando, de fondo, los valores liberales fundacionales del proceso de la industrialización y su relación con la democracia.

Ya no se trataba, solamente, del problema capitalismo versus comunismo o nazismo, sino de la postura social y política que debían difundir explícitamente las compañías en medio de las turbulencias de la guerra. Para las multinacionales esta idea resultaba compleja dado que se relacionaban con gobiernos y Estados de todo el globo. En este sentido, además, las empresas norteamericanas terminaban representando directamente al país en el extranjero, lo que les daba un rol para el cual no estaban preparadas. El caso de la SONJ resultaba además particularmente complejo porque Nelson A. Rockefeller, uno de sus grandes accionistas, formaba parte del gobierno de Roosevelt, en los Estados Unidos, como director de la OIAA. A finales de los años treinta e inicios de los cuarenta, Roosevelt había iniciado una transformación en las relaciones bilaterales entre los países latinoamericanos y los Estados Unidos, a partir de su programa de políticas de relaciones internacionales conocido como The Good Neighbor policy. Este contexto «integracionista» y «cooperativo» influyó en el cambio que tuvieron que dar las grandes corporaciones norteamericanas en su relación con los países extranjeros de América Latina donde tenían influencia ${ }^{24}$.

El impacto de esta política en América Latina estuvo condicionado por la respuesta específica de los gobiernos y las sociedades de esta región del mundo. Por ejemplo, en Colombia la relación con los Estados Unidos fluctuaba políticamente dependiendo el gobernante de turno. En el caso del presidente Eduardo Santos, con quien comenzó la aplicación de las estrategias, existía una simpatía clara, como lo señala David Bushnell,

24 Véase Ardila, 1990. 
con la visión democrática e integracionista que buscaba difundir el amigo del norte ${ }^{25}$. Fue en 1938 cuando se instaló en Bogotá el primer embajador de los Estados Unidos quien consideraba a Colombia, como le escribió al presidente Roosevelt, «la nación más democrática de Sudamérica» ${ }^{26}$. Pero The Good Neighbor policy tenía alcances mayores. Para Cramer y Prutsch, la creación de la OIAA estuvo amarrada, a pesar de su articulación con políticas previas de tipo económico y social, a propósitos de seguridad enmarcados en el contexto de la Segunda Guerra Mundial. El gobierno puso a Nelson A. Rockefeller a cargo de la oficina, que fue cerrada en 1946, buscando fortalecer los lazos estratégicos con América Latina en distintas áreas, pero insistiendo, particularmente, en el problema del reconocimiento identitario americanista, contra la amenazante influencia de los discursos alemanes y soviéticos ${ }^{27}$.

En todo caso, si la propuesta de los Estados Unidos tuvo algún éxito, en la década de los cuarenta y la posguerra, se relacionó, además de los factores políticos y militares, con la construcción del imaginario de la hegemonía estadounidense, la ideología de la americanización. Estados Unidos representaba lo mejor de los valores liberales de la democracia, una cultura moderna e incluyente y unas relaciones internacionales inmejorables con sus amigos. De ahí que la idea de construir unas «Américas Unidas», de integrar a los Estados Unidos y América Latina, a partir de la gestión de la OIAA, formaba parte de este tipo de estrategias, en las que no solo participarían actores políticos sino también culturales y sociales. Uno de los objetivos fundamentales de la OIAA, como lo señalan Cramer y Prutsch, fue «la construcción de una narrativa panamericana que implicó dificultades de representación que fueron difíciles de superar» ${ }^{28}$; es decir, una narrativa al mismo tiempo sofisticada, pero inocente y entretenida, que apelara a los valores de identidad más arraigados, así tuvieran un contenido altamente estereotipado. Pero, al principio, esta construcción no tuvo mucho efecto porque no surgía, en lo más mínimo, de un sentir común sino de la mirada sesgada de los norteamericanos. La OIAA aprendió la lección y comenzó a apelar a una interacción más fuerte con la cultura de América Latina, tanto en la investigación como en la producción de las piezas culturales.

\footnotetext{
25 Bushnell, 1984, p. 17.

26 Bushnell, 1984, p. 25.

27 Cramer and Prutsch, 2012, pp. 5-17.

${ }^{28}$ Cramer and Prutsch, 2012, p, 35, traducción propia.
} 
La nueva política de relaciones internacionales, de diplomacia, como lo explica Fernando Purcell contrastaba con cierto patrón de crecimiento del «antiamericanismo» y del pronacionalismo en varios países de la región. El programa de Roosevelt era, en buena de medida, un proyecto de propaganda que buscaba fortalecer, sobre todo, la imagen de los Estados Unidos y generar una nueva imagen de Latinoamérica para la opinión pública norteamericana. Esto implicó que el proyecto tenía también un carácter comunicativo ${ }^{29}$. En este sentido, es muy importante señalar que $E l$ Proyecto Fotográfico de la Standard Oil Company (New Jersey) comenzó a ejecutarse cuando Nelson A. Rockefeller era director de la OIAA. Rockefeller se había convertido en el principal enlace político entre América Latina y los Estados Unidos, a partir de su experiencia como parte de la Familia Rockefeller, dueña, entre otras empresas, de la Standard Oil Company (New Jersey), que controlaba la industria petrolera en todo el norte de Sudamérica.

El papel de Nelson A. Rockefeller en la contratación de Roy E. Stryker, el creador del Proyecto Fotográfico de la Standard Oil Company (New Jersey), fue registrado por el FILM DAILY, del 16 de octubre de 1943. Lo que resulta muy llamativo de la publicación es la sugestiva idea de que, en alguna medida, el papel que tenía la OIAA, antes CIAA, en las políticas de relaciones internacionales con América Latina lo iba a desempeñar la Standard Oil Company (New Jersey), a partir del proyecto fotográfico, dirigido por Stryker, cuyo trabajo, como lo sugiere el medio, fue uno de los pilares de los proyectos de propaganda de Roosevelt: «No hemos visto a Roy desde que fue a Standard Oil, pero apostamos a que la mano de Nelson Rockefeller está detrás de la cita. Roy hizo un excelente trabajo en la CIAA de Rockefeller mientras estaba en Washington, y Rockefeller sin duda pensó que Roy es el hombre ideal para construir un archivo de imágenes fijas en América del Sur y América Central» ${ }^{30}$.

La ecuación gobiernos-estados-industria-sociedad-cultura resultaba, por lo menos, llamativa, lo que le daba al Proyecto fotográfico de la Standard Oil Company (New Jersey) una importancia que superaba la sola perspectiva empresarial y comercial, y funcionaba como una nueva puerta de entrada a Sudamérica para enfrentar los problemas de imagen. Justamente, este artículo muestra que El Proyecto Fotográfico de la Standard Oil Com-

29 Purcell, 2010, pp. 489-492.

30 Newmyer, 1943, traducción propia. 
pany (New Jersey), desarrollado entre 1943 y 1950, intentó construir un mecanismo distinto, de naturaleza contradictoria, que buscaba generar un proceso de integración social, cultural y económica, rompiendo, en buena medida, con los paradigmas de las políticas tradicionales de relaciones internacionales, incluso las oficiales, con todas las paradojas que eso encarna.

Los proyectos de propaganda de Roosevelt buscaban resignificar el papel central del consenso nacional en la construcción de la sociedad, pero los proyectos de la petrolera SONJ tenían alcances transnacionales. Si bien se podría argumentar que era lógico que el gobierno norteamericano se viera favorecido por los proyectos de la SONJ, por ejemplo desde el punto de vista geopolítico; lo que no resulta tan claro es por qué la apuesta de la SONJ no buscaba, por lo menos explícitamente, fortalecer una postura americanista, sino consolidar la idea de un consenso y reconocimiento sociocultural transnacional. La pregunta, difícil de responder, es si el Estado norteamericano se estaba aprovechando de los proyectos de la SONJ, todo con la intermediación de Nelson A. Rockefeller, o si era la SONJ quien se aprovechaba del Estado. Al final podría resultar que el beneficio fuera mutuo, pero los caminos para alcanzarlo eran distintos. Las 67.000 mil fotografías que produjo, procesó, archivó y distribuyó, el proyecto alrededor del mundo, representan una visión narrativa única en la historia de la comunicación visual, que creó un nuevo régimen de lo visible en la civilización occidental. En el caso de América Latina se produjeron 4563 fotografías documentales industriales de Colombia, Perú y Venezuela, entre 1943 y 1950 que se encuentran catalogadas en el archivo Standard Oil (New Jersey) Collection.

\section{La revolución de las imágenes en la comunicación corporativa: el proyecto visual}

Elmo Roper, como parte de las recomendaciones para iniciar una nueva política de relaciones públicas para la SONJ planteó, de entrada, la necesidad de atender, en los procesos de comunicación institucional, a las actitudes y las impresiones de la gente. Conociendo las urgencias de la compañía, tanto Newsom como Roper, siguiendo ideas de Edward Stanley, comenzaron a interiorizar el discurso de la importancia de las imágenes, las «ilusiones ópticas», en la construcción de la opinión del público, partiendo de la idea de que la percepción humana dependía de «pedazos de evidencia» que permitían construir una verdad factual y que además la 
construcción de los hechos dependía de un montaje selectivo de imágenes que lograría construir no solo opiniones racionales, sino además imágenes mentales, impresiones y reacciones, más relacionadas con actitudes emocionales $^{31}$. Las imágenes, tanto en sentido general como de uso visual específico, serían muy importantes porque permitirían movilizar las evidencias, selectivamente, sobre los hechos reales, sin tener que reconstruir todos los hechos por completo. Ante la mala reputación que tenía la SONJ, que además era considerada como un gran monstruo corporativo, se buscó plantear un giro en la política de relaciones públicas que buscara modificar las estrategias: se trataba de crear un «montaje» de imágenes que fusionadas generaran una nueva impresión de la compañía.

La SONJ ya había comenzado, desde inicios de los años cuarenta, antes del inicio de su megaproyecto fotográfico, a utilizar imágenes visuales de artistas y textos literarios para darle un nuevo sentido a la información difundida por medio de distintas publicaciones. Los usos propagandísticos y publicitarios de las imágenes, fotográficas, cinematográficas o pictóricas, no resultaban nada nuevo ni en el ámbito político, ni en el económico. Desde los años veinte, del siglo Xx, la idea de construir la imagen de políticos, de empresas o de Estados, estaba presente en los departamentos de prensa y de relaciones públicas de políticos e industriales y las imágenes visuales se convirtieron, sistemáticamente, en el medio favorito. Pero, para Ewen, la experiencia de «masturbation of the eye» presente en las estrategias de persuasión, según la gráfica descripción de Georges Duhamel, en los años veinte, resultaba algo incómoda para la sociedad norteamericana justamente por la poca efectividad que la retórica directa había tenido en los programas de comunicación política o publicitaria; y por, la desconfianza que generaban, en la misma opinión pública, las estrategias y técnicas de manipulación de la opinión y el comportamiento ${ }^{32}$.

Las técnicas de comunicación visual ya habían sido apropiadas por las instituciones estatales a finales de la década de los treinta e inicios de los años cuarenta del siglo XX. Por ejemplo, resultaba públicamente conocido el uso de las imágenes, principalmente fotográficas, para efectos retóricos, en un marco organizacional tan específico como la Office of War Information, OWI, la oficina de prensa de Estados Unidos durante la Segunda Guerra Mundial, para llevar a cabo, según ese gobierno, objetivos

\footnotetext{
31 Newsom, 1942, p. 3.

32 Ewen, 1996, p. 191.
} 
precisos para la continuidad de la sociedad democrática occidental y el mantenimiento del orden transnacional bajo el dominio americano. Para la OWI, las imágenes eran una parte muy importante de la información por lo que la oficina, por medio de Roy E. Stryker, quien en ese momento se encontraba adscrito a la OWI, tenía sus propios documentos de políticas de uso de imagen, que incluían «procedimientos científicos» de uso de archivo para comunicar cada uno de los aspectos de la guerra, buscando la construcción de imágenes mentales soportadas en fotografías: «Una fotografía es lo más cercano que tenemos a la realidad. El grado de impacto depende, como en el uso de las palabras, de la forma en que se usan las fotografías: obtener las fotografías correctas en la secuencia correcta y con las palabras correctas $»^{33}$.

Así, el 19 de noviembre de 1943 la SONJ crea un nuevo departamento de relaciones públicas en cabeza de Roper. La meta de Roper era hacer coincidir la fe de la opinión pública en el sistema capitalista con el deseo corporativo, en este caso de la SONJ, de que la gente tuviera una supuesta seguridad económica. La pregunta de fondo era cómo debería redefinir la Standard Oil su imagen pública. Para el trabajo, Roper contaría con el analista Newson, un psicólogo social experto en «human engineering», como consultor general de relaciones públicas de la compañía, siguiendo a la cabeza Robert Haslam. Sería Newson quien contrataría, poco después, a Stryker, para llevar a cabo el proyecto fotográfico. El objetivo fundamental era insertar la imagen fotográfica en la conciencia de la propia industria y de la propia sociedad, de tal modo que no se tratara de simples efectos, trucos o técnicas. El caso que estamos analizando redefiniría la comunicación visual a partir de la construcción de la categoría fotografía documental industrial. Paradójicamente, como lo señala en su tesis de maestría Steven W. Plattner, el único investigador que estudio una parte del proyecto, el estudio de casos de este tipo se ha obviado sistemáticamente, debido, en parte, a la desconfianza que genera el hecho de que las corporaciones capitalistas estén detrás de la construcción de uno de los modelos epistémicos relevantes para el desarrollo de las democracias modernas ${ }^{34}$.

El propio Stryker señalaría, en el documento inédito «Photography and Industrial Public Relations», escrito en 1948, la importancia del proyecto para comprender, casi sociológicamente, la complejidad de las re-

\footnotetext{
33 Office of War Information, n.d., p. 2, traducción propia.

34 Plattner, 1981, p. 4.
} 
laciones entre la industria, el trabajo del hombre y la naturaleza. La estrategia de relaciones públicas, desde la perspectiva de Stryker, dependió de los usos que la SONJ hizo de un material que, previamente, contenía mucho más que información publicitaria sobre la compañía, lo que posibilitó el desarrollo de un modelo inédito de relaciones públicas (PR) basado en una conciencia específica de la historia industrial: «En Jersey Standard, la fotografía ha tenido la oportunidad de contar una gran parte de la historia industrial. Hemos creado un archivo considerable sobre este tema central: que la historia del petróleo es parte del esfuerzo constante del hombre por dominar y utilizar su entorno» ${ }^{35}$.

Roy E. Stryker, nacido el 11 de mayo de 1893 en Great Bend, Kansas, se graduó de economía en Columbia University, como lo indica en uno de sus perfiles autobiográficos ${ }^{36}$, donde colaboró como coautor e ilustrador del libro American Economic Life con Rexford G. Tugwell, su futuro jefe en el estudiado proyecto fotográfico de la Farm Security Administration, FSA, del gobierno de Roosevelt; y donde comenzó a conectar, en las clases que dictaba, las imágenes, principalmente fotográficas, con el universo económico. El descubrimiento más importante de Stryker en su etapa de formación fue comprender, según su alumno Calvin Kytle, concepción que sería vital en sus proyectos futuros, que la economía trataba sobre seres humanos y no sobre dinero ${ }^{37}$.

El esquema de funcionamiento que Stryker montó para la SONJ era similar al que utilizó, siendo el jefe, para el programa fotográfico de la «Historical Section» de la FSA, desarrollado durante el gobierno de Franklin D. Roosevelt, como parte de un programa de cambio social que se construyó, en parte, con base en un esquema de propaganda visual humanista que les permitió a los americanos «conocerse a sí mismos» para concretar un nuevo pacto social. El acervo fotográfico de la FSA, como lo señaló F. Jack Hurley, en el análisis más cercano al proyecto original, se constituye en el retrato de una década resultado de un proyecto fotográfico documental usado al servicio de un programa político ${ }^{38}$. Resultaba, entonces, muy lógico que Newsom buscara la ayuda de Stryker para consolidar un archivo documental que permitiera, sobre el fundamento del rigor histórico, construir una nueva base de datos que permitiera desarrollar

\footnotetext{
35 Stryker, 1948, p. 3, traducción propia.

36 Véase Stryker, n.d.

37 Kytle, 1977, p. 4.

38 Véase Hurley, 1974.
} 
esta nueva imagen de la compañía. El lenguaje documental, en este sentido, resultaría fundamental para la estrategia, dada su capacidad de transmitir la «verdad».

El memorando llamado Attached are a few notes on what I think should be done, and the way it could be accomplished es un documento de naturaleza conceptual y técnica que permite identificar la forma como Stryker comenzaba, desde lo teórico y lo operativo, a generar una estrategia de comunicación, que adaptaba los principios fundamentales del proyecto desarrollado para el gobierno de Roosevelt a una propuesta de relaciones públicas, en el campo del capital privado ${ }^{39}$. Stryker destaca, de entrada, la importancia de la función de la fotografía en las relaciones públicas, dada su capacidad, como lenguaje, para combinar el poder de la persuasión con la inmediatez de la experiencia real. Pero concretamente, Stryker señala que entre las distintas clases de fotografía de relaciones públicas - News, Feature, Studio y Documentary - , la fotografía documental tiene ventajas comparativas asociadas a los usos y efectos de las imágenes: «La fotografía documental es el registro e interpretación de todo el entorno en una extensa serie de imágenes ${ }^{40}$.

En ese memorándum base Stryker explica, detalladamente, por qué resultaba fundamental construir un archivo documental extenso y sistemático para lograr que las imágenes produjeran los efectos deseados, en un claro marco institucional. Para Stryker, una fotografía aislada no produce ningún efecto persuasivo o retórico. Las imágenes, que resultan de un proceso organizado de producción, deben insertarse en un sistema efectivo de distribución y circulación que permita ampliar el rango de uso: «Un archivo documental - una vez ha crecido hasta el punto donde se tiene una cobertura adecuada de los ejes principales del material - sirve prácticamente para todos los canales de relaciones públicas, con la excepción de la radio. A medida que crece y amplía su alcance, también puede aumentar el rango de su utilidad» ${ }^{41}$. La fotografía podía ser usada, en este sentido para múltiples medios de comunicación: revistas, educación, museos, investigadores, libros, exposiciones.

Stryker proponía trabajar a partir de un direccionamiento que partía de la articulación entre un personal especializado, con una clara división del trabajo, una estructura de producción de imágenes completamente or-

\footnotetext{
39 Stryker, 1943, p. 1.

40 Stryker, 1943, p. 1, traducción propia.

${ }^{41}$ Stryker, 1943, p. 2, traducción propia.
} 
ganizada, y unos claros objetivos y planes. La idea de Stryker era producir las primeras 10.000 fotos, durante 15 meses, cubriendo la actividad petrolera en el Estados Unidos continental, aunque el archivo solo se llegaría a constituir como tal a partir de las 25.000 imágenes $^{42}$. Luego se cubriría el resto del mundo. Una de las complejidades que tenía el proyecto era la movilización de recursos materiales y humanos a las distintas regiones del mundo donde se pretendía tomar las fotografías, lo que demandó, además, la puesta en marcha de estrategias logísticas, para el envío y recepción de suministros y resultados; y estrategias de comunicación - vía carta, telegrama, teléfono - para el control, manejo y solución de problemas en campo. El proyecto se extendió por todo Estados Unidos y se ejecutó integralmente en Colombia, Venezuela, Perú, Canadá, Aruba, Arabia Saudita, Francia, Bélgica, y parcialmente en otros países ${ }^{43}$.

El equipo que comenzó a trabajar en el proyecto estaba constituido por 12 empleados, 4 fotógrafos, 2 técnicos de laboratorio, 1 bibliotecario, 1 archivista, 2 secretarias, y el jefe de la unidad, que debían estar tiempo completo disponibles para Stryker, con un significativo presupuesto, para la época, cercano a los \$1553.30 dólares por semana, destinados a personal, materiales y equipos. Aunque cada empleado de la empresa resultaba fundamental para Stryker, sin duda los fotógrafos jugaban un papel central en el proyecto ${ }^{44}$. Después de 6 meses de trabajo se comprobó que la estructura de funcionamiento estaba marchando como Stryker lo deseaba. El resumen de los resultados del 28 de marzo de 1944 revela los efectos de la estructura institucional ${ }^{45}$. Finalmente, con el proyecto estructurado, Stryker iniciaría la segunda fase, que consistía en enviar a los distintos fotógrafos a todos los lugares del mundo en los cuales la SONJ tenía exploración petrolera. Stryker logró, otra vez, que muchos de los mejores fotógrafos de la historia trabajaran para el proyecto y lanzó, a la escena fotográfica, a otros que se convertirían posteriormente en reconocidos fotógrafos. El grupo final incluyó a Berenice Abbott, Charlotte Brooks, Esther Bubley, John Collier Jr., Harold Corsini, Arnold Eagle, Morris Engel, Elliot Erwitt, Russell Lee, Sol Lisbohn, Lisette Model, Gordon Parks, Martha McMillan Roberts, Louise Rosskam, Edwin Rosskam, Charles

42 Stryker, 1943, p. 2.

43 Public Relations Department, n.d., pp. 4-5.

44 Plattner, 1983, p. 14.

45 Véase The Work of the Photographic Department As It Appears After Six Months'Experience, 1944. 
Rotkin, John Vachon y Todd Webb. A Colombia, Venezuela y Perú llegaron John Collier Jr. y John Vachon, cuyas imágenes sintetizarían el sentido del Proyecto Fotográfico de la Standard Oil Company (New Jersey), desde una perspectiva geopolítica transnacional.

La selección de John Collier Jr. y John Vachon, para ejecutar El Proyecto Fotográfico de la Standard Oil Company (New Jersey) en América del Sur no resultó para nada accidental, ya que se trató de los dos fotógrafos que más conocimiento, desde lo visual, lo antropológico y lo sociológico, tenían sobre el problema de las culturas latinoamericanas. La extensa obra fotográfica, de estos dos fotógrafos, se constituye en el acervo sistematizado más grande que existe en los Estados Unidos sobre esta región del mundo en ese particular periodo de la historia del hemisferio occidental. Las fotografías de Collier Jr. y de Vachon fueron sistemáticamente utilizadas por la SONJ, y posteriormente por la ExxonMobil, principalmente para difundir información visual sobre un conjunto vasto de cuestiones sobre la actividad petrolera y la vida en América Latina, en la revista The Lamp y en distintas publicaciones internas y externas. Colombia, Venezuela y Perú entraban, por primera vez, de manera sistemática y racional al régimen de representación visual del capitalismo industrializado transnacional. El 30 de junio de 1950, luego de constituir un complejo y extenso archivo fotográfico, Stryker renunció a la SONJ, tras siete años manejando el proyecto fotográfico más grande de la historia emprendido por una corporación privada ${ }^{46}$.

\section{Fotografía documental industrial y el mito racionalista de una «democracia capitalista transnacional»}

En Photography and Industrial Public Relations, Stryker plantea que ni la publicidad, ni las declaraciones institucionales, ni los infomerciales han logrado, antes del Proyecto Fotográfico de la Standard Oil Company (New Jersey), crear un concepto preciso y eficaz de la historia de la industria - qué es, qué hace y cómo lo hace- presentado de manera convincente e interesante a las mentes de los públicos, quienes poseen gustos, ojos y oídos diferenciados. Para Stryker, la solución estaba en la formulación de una estrategia de relaciones públicas que debía construir un rigu-

46 Véase Plattner, 1981. 
roso y creativo autorretrato visual que lograra conectar a la industria con la sociedad: «A medida que la industria se da cuenta de que el autorretrato sincero es el mejor medio para impartir o transmitir a otros sus conceptos de sí misma, la fotografía está asumiendo más importancia en las relaciones públicas» ${ }^{47}$.

Para Stryker la fotografía documental industrial logró captar un rostro único del funcionamiento de la industria petrolera cuya complejidad, naturaleza y belleza, producto del esfuerzo constante del hombre por dominar y usar su medio ambiente, apenas conocían los ciudadanos corrientes. De entrada, El Proyecto Fotográfico de la Standard Oil Company (New Jersey) asignó una función sustantiva a los usos de la fotografía documental industrial que consistía en la comprensión social del papel fundamental de la industria en la tecnificada sociedad moderna, y en la construcción de un tipo de identidad, no nacional, soportada en una democracia transnacional industrializada, cuyos lazos sociales estuvieran anclados a un sistema racional humanista de conocimiento ${ }^{48}$.

Una función de este tipo supuso, por una parte, un ejercicio de autoconciencia y análisis de la estructura oculta de relaciones que constituye el capitalismo moderno industrializado; y, por otro lado, un interés por integrar nuevas sociedades y culturas, casi todas marginadas del régimen de representación visual transnacional, a un nuevo espacio de consenso social y económico, pero sobre todo imaginario. El proyecto posibilitó, en este sentido, la construcción de una imagen visual de distintos grupos humanos y sociedades, con las contradicciones que ello implicaba dado que se trataba de un proyecto que buscaba generar un nuevo mapa del mundo donde entraba de manera hegemónica aquello que ingresaba al archivo: «Las fotografías ayudan a Jersey a decirle a la gente en todas partes que: el petróleo es internacional, el petróleo suministra energía para el bienestar humano, el petróleo crea empleo humano, el progreso del petróleo viene a través de la investigación ${ }^{49}$. En principio se declara que la fotografía documental industrial permite representar muchos aspectos, rostros, de la industria que nunca había sido posible ver de esa manera. La fotografía se convierte en el medio para revelar el funcionamiento inconsciente del capitalismo industrial desde su propio núcleo.

47 Stryker, 1948, p. 1, traducción propia.

48 Stryker, 1947, p. 5, traducción propia.

49 The Work of the Photographic Department As It Appears After Six Months'Experience, 1944, p. 3, traducción propia. 
Con El Proyecto Fotográfico de la Standard Oil Company (New Jersey), Stryker da un paso más en la historia del documentalismo fotográfico, modificando el propio sentido de este tipo de imagen constituido, previamente, en el proyecto de la Farm Security Administration de Roosevelt. El nuevo enfoque parece superar la idea de que la imagen fotográfica documental tiene solo un efecto emocional y sentimental, dramático, dado por su naturaleza humanista. En el desarrollo histórico de la fotografía documental se cruzaría un elemento inesperado, que le daría un sentido específico nuevo, asociado a otros usos y funciones: los industriales. Las visiones tanto fáctico, objetivistas, como dramáticas, emotivo-sentimentales, que se siguieron explotando de manera cada vez más sofisticada a lo largo del siglo Xx, se subordinarían, en este caso, a una visión racional y técnica, que llevaría la idea de documentalismo a otro nivel.

Para cumplir esa función, en términos generales, se utilizó la estrategia del Coverage, que implicaba una visión ampliada del lugar de la industria en la sociedad moderna tanto en su estructura productiva como en su estructura de consumo, para llegar a cada uno de los detalles que constituían la industria petrolera en el presente: «Pero para nosotros, en una democracia, es necesario trabajar dentro del alcance del presente para poder trabajar el todo. El documento, entonces, es el que da detalles esenciales para el presente. Estos detalles se encontrarán en los datos sociales y vitales que en su totalidad revelan una forma de vida ${ }^{50}$. Se puede observar que los términos que usa Stryker van redefiniendo la fotografía documental en torno a su función industrial, acomodada míticamente para «fortalecer la democracia». La forma comienza a estar subordinada a la función industrial racional y los componentes puramente dramáticos y artísticos comienzan a perder fuerza ${ }^{51}$. Lo potente de esta declaración es que la fotografía documental industrial se constituye, para la compañía, en el medio de comunicación que, finalmente, logra comunicar, según ellos, la verdadera realidad sobre el funcionamiento y el papel de la industria petrolera en la vida humana.

Pero la funcionalidad y el sentido del proyecto, asumida casi como un servicio público, había comenzado a generar preguntas entre las directivas de la compañía, quienes después de los primeros cinco años de funcionamiento albergaban dudas sobre la estrategia que, concretada por Stryker,

\footnotetext{
50 Stryker and Locke, n.d., p. 6, traducción propia.

51 Stryker, 1947, p. 3.
} 
había planeado Earl Newsom y George H. Freyermuth, quienes estaban en la cabeza del programa de relaciones públicas de la SONJ, que buscaba cambiar, definitivamente, la imagen de la compañía ante el público, por lo menos en el corto o mediano plazo. Plattner resalta las dudas que tenía la compañía sobre la efectividad del uso del archivo en el mejoramiento de su imagen frente al público, principalmente de acuerdo a los resultados de las encuestas realizadas, periódicamente, por su consultora de relaciones públicas, por medio de Elmo Roper: «Sin medios disponibles para medir el grado en que la difusión de las fotografías de Standard Oil afectó la imagen pública de la compañía, los directores aparentemente encontraron difícil justificar la financiación del proyecto de Stryker en los altos niveles que había disfrutado en años anteriores» ${ }^{52}$. Según Plattner la imagen de la compañía se había mantenido baja durante el periodo, con un ligero crecimiento para 1948; lo cual suponía que el papel del Proyecto Fotográfico de la Standard Oil Company (New Jersey) no había resultado decisivo para cambiar la curva: «Presumiblemente, el fracaso de la compañía para mejorar su relación con el público estuvo vinculado a su imagen tradicional desde la era de John D. Rockefeller, Sr.; en 1948, Standard Oil todavía evocaba imágenes de "Rockefeller, Trust, Big Business, Big Profits"» ${ }^{53}$.

Plattner también señalaría, tras entrevistar a varios de los fotógrafos que participaron en el proyecto, que, a pesar de las buenas intenciones de Stryker, las fotografías del archivo generaban cierta falta de credibilidad, al asociarse con los créditos de la Standard Oil Company (New Jersey). Los propios fotógrafos instrumentalizaban, incluso en términos económicos, el trabajo para la SONJ, y la demonizaban con frecuencia. Para Plattner, ese prejuicio también persistía en la mente de editores y artistas reconocidos: «Sin embargo, la mayoría de las otras revistas de circulación masiva evitaron las imágenes de fuentes industriales por completo debido al problema de credibilidad» ${ }^{54}$. Pero Stryker insistía en que este cambio epistemológico, respecto al uso de la fotografía documental industrial, suponía un humanismo racional que imponía una nueva visión sobre la relación entre industria, democracia y sociedad, contra la agencia permanente de los programas nacionalistas. Esa imagen racional buscaba convencer míticamente de que la industria jugaba un papel determinante y positivo para la democracia.

\footnotetext{
52 Plattner, 1983, p. 24, traducción propia.

53 Plattner, 1983, p. 24, traducción propia.

54 Plattner, 1981, p. 123, traducción propia.
} 
En el caso analizado resulta fundamental, en este sentido, comprender la manera cómo un tipo de imagen, la imagen documental, tan asociada a efectos dramáticos y fácticos, de naturaleza mimética, objetivista y naturalista, es redefinida y adecuada, en su uso institucional, para nuevos fines implicados en este proyecto de documentalismo industrial. No se puede, sin embargo, como lo advierte W.J.T. Mitchell, caer en las trampas comunes de la iconología que lleva, en ocasiones, a desprender de los análisis empíricos específicos, excesivas generalizaciones y pretenciones de verdad categóricas ${ }^{55}$. El problema de la relación entre la fotografía y lo técnico fue abordado de manera precisa por Walter Benjamin para explicar las transformaciones estructurales de los procesos de comunicación humana, generadas por el proceso de industrialización, ocurridos en la era moderna. La construcción de los lazos sociales, los sistemas de representación colectiva, las formas básicas de comunicación y los mecanismos de construcción del conocimiento sobre la realidad se vieron alterados, casi de manera absoluta, por el dispositivo técnico que permitía reproducir infinita y exactamente una imagen, un texto, un objeto, una forma. La fotografía representaría, en este sentido, el medio técnico reproductivo por definición ${ }^{56}$.

El énfasis del análisis de Benjamin iba mucho más allá del uso instrumental de los medios para fines políticos, económicos y sociales. Benjamin lo que señala es que en los procesos de comunicación moderna lo que se modificó o alteró son las categorías perceptivas, sociales y representacionales - de tiempo, espacio y acción - más fundamentales de la vida humana. Para Benjamin la reproductibilidad técnica creó, literalmente, un sensorium distinto. De ahí que, para un proyecto transnacional de relaciones públicas, tal como el que planteo Stryker, la fotografía, como medio técnico, resultó ser el medio ideal, pero no porque permitiera adoctrinar o persuadir a los grupos humanos respecto a las bondades de la industria petrolera y de la industria en general en las sociedades democráticas modernas, sino porque, justamente, al poner en funcionamiento un megaproyecto de comunicación visual, técnico e industrializado, de este tipo, el funcionamiento de la industria se revelaría en su propia dinámica racional.

Este aparato discursivo resultaba tan sofisticado, en este sentido, que hacía explícitas las transformaciones epistémicas, sensoriales y perceptivas que el capitalismo industrializado estaba trayendo a la vida hu-

55 Mitchell, 2009, p. 27.

56 Véase Benjamin, 2004. 
mana. Justamente el análisis del proyecto lo que revela son las propias transformaciones epistemológicas que están implicadas en su puesta en marcha. En este sentido, siguiendo las ideas de Brea, El Proyecto Fotográfico de la Standard Oil Company (New Jersey) estaba inserto en una industria de la conciencia: «Para ella, no solo para sus productos, sino para nuestra propia conciencia de ellos, aumentará - como para el pensamiento, dirá nuevamente Benjamin - la importancia de la estadística: la fuerza de lo abundante y la cantidad decidirán la forma de su presencia en el mundo, frente al viejo régimen de las singularidades santuarias, exclusivas ${ }^{57}$. Paradójicamente, la construcción de una conciencia sobre la industria y la modificación epistémica racional se alimentaría al mismo tiempo de la explotación del aspecto inconsciente del dispositivo fotográfico, definido, por el propio Benjamin como inconsciente óptico. La fotografía, en este sentido, aspecto que tenía muy claro Stryker para el El Proyecto Fotográfico de la Standard Oil Company (New Jersey) permitiría revelar, conscientemente, el propio inconsciente visual del capitalismo industrializado, representado en la historia de la industria petrolera transnacional.

\section{Algunas conclusiones}

Las relaciones públicas habían sido concebidas, hasta finales de los años treinta, del siglo XX, como estrategias verticales de comunicación de las grandes corporaciones industriales con el gran público, atendiendo principalmente a demandas publicitarias y a resolución de conflictos de imagen, utilizando medios y lenguajes simples y llanos. Pero la nueva política institucional, en este caso de la SONJ, apoyada en El Proyecto Fotográfico de la Standard Oil Company (New Jersey), supuso una redefinición del concepto. Las estrategias de comunicación visual, desde la perspectiva de Stryker, superaron la visión propagandística, eliminando la idea de abastecimiento de información para los medios de comunicación de masas, y enfatizando, más bien, en la producción permanente de dispositivos complejos que se conectaran con esferas artísticas, educativas, sociales, políticas y por supuesto económicas; y que buscaran establecer una comunicación con diversos públicos.

57 Brea, 2010, p. 48. 
Estos cambios en la estructura comunicacional de la compañía pretendían, también, redefinir las relaciones públicas internacionales entre la poderosa empresa norteamericana y los Estados nacionales, adquiriendo una función sustantiva, otorgada directa e indirectamente por la sociedad y el propio gobierno de los Estados Unidos, para fortalecer el lazo diplomático y comercial entre Norteamérica y los países productores de petróleo. El caso de América Latina resultó particularmente complejo, en este sentido, porque uno de los grandes accionistas de la Standard Oil Company, en los años de desarrollo del proyecto, formaba parte, al mismo tiempo, del gobierno de Roosevelt, en los Estados Unidos, como director de la OIAA: Nelson A. Rockefeller.

El desarrollo del Proyecto Fotográfico de la Standard Oil Company (New Jersey) resultó, en este sentido, muy paradójico porque, por una parte, revelaba una nueva estrategia para preservar el clásico modelo colonial estadounidense, ejecutado principalmente con los países más subdesarrollados, pero que tenían un gran potencial económico. Pero, al mismo tiempo, por otra parte, el esfuerzo de la SONJ, para desarrollar este proyecto, supuso una transformación en la propia mirada del papel de la industria en la sociedad, que rechazaba el logocentrismo nacionalista, populista y folclorista, buscando que, los países productores de petróleo donde la compañía tenía incidencia, ingresaran a un proceso de modernidad civilizatoria y compartieran un complejo espacio de consenso social, en torno a una identidad transnacional, cuya visión de la «democracia industrial» y tecnificada se anclara a un sistema racional humanista de conocimiento, así fuera de manera imaginaria.

Esta idea superaba largamente el sentido del programa de políticas de relaciones internacionales de Franklin D. Roosevelt, conocido como The Good Neighbor policy, para el caso de América Latina. Al tratarse de un sistema de reorganización de las representaciones, El Proyecto Fotográfico de la Standard Oil Company (New Jersey) buscaba movilizar una visión positiva de la «democracia» capitalista transnacional, en torno a la historia del petróleo, utilizando la fotografía documental industrial como el medio para construir una nueva imagen mental colectiva del lugar de la industria en la sociedad moderna, con todas las paradojas que eso implicaba.

Este proceso terminó siendo contradictorio, en su devenir, porque, por una parte, la funcionalidad y el sentido del proyecto, asumida casi como un «servicio público», había comenzado a generar dudas entre las directivas de la SONJ, después de los primeros cinco años de funcionamiento, sobre su efectividad para mejorar la imagen de la compañía ante el público, por lo menos en el corto o mediano plazo. Los resultados en el me- 
joramiento no fueron los esperados según las encuestas realizadas, periódicamente, aunque tuvo un ligero aumento hacia 1948. Pero, por otro lado, el impacto real del proyecto se centró en su papel revolucionario para generar una serie de transformaciones epistemológicas en el campo de las relaciones entre la comunicación visual y las ciencias sociales, la antropología y la historia, bajo el concepto fotografía documental industrial, que modificaría el propio campo de las relaciones públicas y revelaría, para el caso estudiado, las contradicciones de las relaciones entre la economía, la democracia y la cultura.

\section{Fuentes}

\section{Archivos}

Roy Stryker (1893-1975) Papers. 1912-1972, Photographic Archives, Special Collections and Archives, University of Louisville, Louisville Ky.

Standard Oil (New Jersey) Collection, Special Collections and Archives, University of Louisville, Louisville Ky.

\section{Documentos primarios}

NEWMYER, Arthur G., [Text from FILM DAILY de October 16, 1943 en una carta para Mr. Earl Newson], October 17, 1943, en Roy STRYKER (1893-1975) PAPERS 1912-1972, 78.9 SERIES I. Correspondence 1942-1948, BOX 4, Folder 5, 1943. JUL-DIC. Photographic Archives. Special Collections and Archives. University of Louisville. Louisville, KY.

Newsom, Earl «Remarks by Mr. Earl Newsom» [Memorando], 1942, 11-02, en Roy STRYKER (1893-1975) PAPERS 1912-1972, 78.9 SERIES II. PART C - G, BOX 7, FOLDER 2, SONJ. II-D.1, 4. Photographic Archives. Special Collections and Archives. University of Louisville. Louisville, KY.

Newsom, Earl, Carta para George Freyermuth, June 7, 1946, en Roy STRYKeR (1893-1975) PAPERS 1912-1972, 78.9 SERIES II. PART C - G, BOX 7, FOLDER 2, SONJ. II-D.1. Photographic Archives. Special Collections and Archives. University of Louisville. Louisville, KY.

OfFICE OF WAR INFORMATION [Memorando de la OWI] (n.d.), en Roy STRYKeR (1893-1975) PAPERS 1912-1972, 78.9 SERIES II. PART C - G, BOX 7, FOLDER 1, OWI. II-C.4. Photographic Archives. Special Collections and Archives. University of Louisville. Louisville, KY. 
Public Relations Department. Standard Oil Company (N.J.). PHOTOGRAPHIC SECTION (n.d.), en Roy STRYKER (1893-1975) PAPERS 1912-1972, 78.9 SERIES II. PART C - G, BOX 7, FOLDER 3, SONJ. II-D.1. Photographic Archives. Special Collections and Archives. University of Louisville. Louisville, KY.

STRYKER, Roy E., MEMORANDUM. TO: MR. EARL NEWSOM. FROM: Roy STRYKER. Attached Are a Few Notes On What I think Should Be Sone, and The Way It Could Be Accomplished, August, 1943, en Roy STRYKER (1893-1975) PAPERS 1912-1972, 78.9 SERIES I. Correspondence 1942-1948, BOX 4, Folder 5, 1943. JUL-DIC. Photographic Archives. Special Collections and Archives. University of Louisville. Louisville, KY.

STRYKER, ROy E., PHOTOGRAPHY AND INDUSTRIAL PUBLIC RELATIONS, Article prepared for Joe Costa [Manuscrito inédito], September 28, 1948, en Roy STRYKER (1893-1975) PAPERS 1912-1972, 78.9 SERIES II. A-C, BOX 6, FOLDER 2, RES PERSONAL. II-B-1. Photographic Archives. Special Collections and Archives. University of Louisville. Louisville, KY.

STRYKER, Roy E., DOCUMENTARY PHOTOGRAPHY IN INDUSTRY, By Roy E. Stryker. From U.S. Camera Annual, 1947, en Roy STRYKER (18931975) PAPERS 1912-1972, 78.9 SERIES II. A-C, BOX 6, FOLDER 2, RES PERSONAL. II-B-1. Photographic Archives. Special Collections and Archives. University of Louisville. Louisville, KY.

STRYKER, Roy E., [Hoja de vida Roy E. Stryker] (n.d.), en Roy STRYKER (18931975) PAPERS 1912-1972, 78.9 SERIES II. A-C, BOX 6, FOLDER 1, RES PERSONAL. II-A-1. Photographic Archives. Special Collections and Archives. University of Louisville. Louisville, KY.

STRYKER, Roy E. and LOCKE, Edwin, DOCUMENTARY PHOTOGRAPHY (n.d.), Roy STRYKER (1893-1975) PAPERS 1912-1972, 78.9 SERIES II. A-C, BOX 6, FOLDER 2, RES PERSONAL. II-B-1. Photographic Archives. Special Collections and Archives. University of Louisville. Louisville, KY.

THE WORK OF THE PHOTOGRAPHIC DEPARTMENT AS IT APPEARS AFTER SIX MONTHS'EXPERIENCE, March 28, 1944, en Roy STRYKER (1893-1975) PAPERS 1912-1972, 78.9 SERIES I. Correspondence 19421948, BOX 4, Folder 7, 1944. Photographic Archives. Special Collections and Archives. University of Louisville. Louisville, KY.

\section{Bibliografía}

ARDILA, Martha, «Diplomacia multilateral durante la segunda administración de Alfonso López Pumarejo (1942-1945)», Análisis Político, N. ․ 10, 1990. 
Las relaciones públicas, la comunicación visual y el mito del capitalismo transnacional ...

AzPíroz, María Luisa, Diplomacia Pública. El Caso de La «Guerra Contra El Terror, Editorial UOC, Barcelona, 2012.

Benjamin, Walter, Sobre La Fotografía, Pre-Textos, Valencia, 2004.

Blair, Anthony, «The Rhetoric of Visual Arguments», En HiLl, Charles \& HelMERs, Marguerite (Eds.), Defining Visual Rhetorics, LEA, New Jersey, 2004, pp. 41-61.

BreA, José L, Las Tres Eras de La Imagen, Akal, Madrid, 2010.

Bushnell, David, Eduardo Santos y La Política Del Buen Vecino 1938-1942, EL ÁNCORA EDITORES, Bogotá, 1984.

Cramer, Gisela, and Prutsch, Ursula, «Nelson A. Rockefeller's Office of Inter-American Affairs and the Quest for Pan-American Unity: An Introductory Essay», In CRAMER, Gisela, and PRUTSCH, Ursula, ;Américas Unidas! Nelson A. Rockefeller's Office of Inter-American Affairs (1940-46), Iberoamericana - Vervuert, Madrid - Frankfurt, 2012, pp. 15-51.

Curran, James, Media and Power, Routledge, New York, 2002.

EwEn, Stuart, PR! A Social History of Spin, BasicBooks, New York, 1996.

Hurley, F. Jack, Portrait of a Decade. Roy Stryker and the Development of Documentary Photography in the Thirties, Louisiana State University Press, Lousiana, 1974.

KYTLE, Calvin, «Roy Stryker: A Tribute», In JAMES C. Anderson, Roy Stryker: The Humane Propagandist, Photographic Archives University of Louisville, Louisville, 1977, pp. 4-7.

Larson, Henrietta, Knowlton, Evelyn, and Popple, Charles, New Horizons 1927-1950. History of Standard Oil Company (New Jersey), Harper \& Row, Publishers, New York, 1971.

LAsswell, Harold, Propaganda Technique in the World War I, Kegan Paul, London, 1927.

LÜBKEN, Uwe, «Playing the Cultural Game: The United States and the Nazi Threat to Latin America», In Cramer, Gisela, and Prutsch, Ursula, ;Américas Unidas! Nelson A. Rockefeller's Office of Inter-American Affairs (1940-46), Iberoamericana - Vervuert, Madrid - Frankfurt, 2012, 53-76.

Mitchell, W.J.T, Teoría de La Imagen, Akal, Madrid, 2009.

NyE, Joseph S., Bound to Lead: The Changing Nature of American Power [Versión Para Kindle], Basic Books, New York, 1990.

Plattner, Steven W., How the Other Half Lived: The Standard Oil Company (New Jersey) Photography Project, 1943-1950 [manuscrito de tesis], The George Washington University, 1981.

PlattNer, Steven W., Roy Stryker: U.S.A., 1943-1950: The Standard Oil (New Jersey) Photography Project, University of Texas Press, Austin, 1983.

Purcell, Fernando, «Cine, Propaganda y El Mundo de Disney En Chile», Historia II, n. ${ }^{\circ} 43,2010$, pp. 487-522. doi:10.4067/S0717-71942010000200005. 
SÁEnz Rovner, Eduardo, Colombia Años 50. Industriales, Política y Diplomacia, Universidad Nacional de Colombia, Bogotá, 2002.

SEIGEL, Micol, «Beyond Compare: Comparative Method after the Transnational Turn» Radical History Review, 91, 2005, pp. 62-90.

Wall, Bennett H., Growth in a Changing Environment. A History of Standard Oil Company (New Jersey) 1950-1972 and Exxon Corporation 1972-1975, McGraw-Hill Book Company, New York, 1988.

\section{Financiación}

Este artículo se deriva del proyecto de investigación COM-70-2016 financiado por la Universidad de La Sabana.

\section{Datos del autor}

Edward Goyeneche-Gómez es Doctor en Historia de la Universidad Nacional de Colombia (2019). Magíster en Sociología (2008) y Comunicador Social-Periodista de la Universidad del Valle (2003). Profesor de planta de la Facultad de Comunicación de la Universidad de La Sabana y Jefe del Departamento de Comunicación Audiovisual. Integrante del grupo de investigación Cultura Audiovisual. Escritor e investigador de los libros Fotografía y Sociedad (2009) y Volver a los clásicos. Teorías de la comunicación y cultura pop (2016). Ganador de la Beca de investigación de Posgrados 2015 del Centro de Estudios Estadounidenses, CEE-Colombia, de la Universidad de los Andes y la Universidad Nacional de Colombia. Trabaja en las líneas de investigación sobre epistemología visual, principalmente de la fotografía y el cine, comunicación y cultura visual y audiovisual, representaciones sociales y colectivas, memoria y antropología visual e historia cultural. 